\title{
Manage Projects Smarter: Picking Tools for Small and Medium-Sized Enterprises
}

\author{
http://dx.doi.org/10.3991/ijac.v5i3.2175 \\ Stefanie Quade,Marcus Birkenkrahe and Frank Habermann \\ Berlin School of Economics and Law, Berlin, Germany
}

\begin{abstract}
Small and medium-sized enterprises (SMEs) are increasingly dealing with international projects and distributed (sometimes even virtual) teams. Consequently, they are looking for project management (PM) tools which fit their respective needs regarding communication and collaboration. Unfortunately, the majority of the PM software available in the market seems to be oversized for this purpose. Instead most project managers are requesting smart solutions that allow quick implementation without any significant organisational or technical change.
\end{abstract}

Within the research project InterComp SME 2.0 we combine theoretical research and real business to develop hands-on solutions for SMEs. This paper describes an effective approach for a "PM Toolbox" that allows finding the right project tool for a specific project need. The toolbox has been developed in due consideration of user stories gained from business practice, a more detailed SME business survey, a theoretical PM meta model and a market of PM tools.

Since the business survey revealed that the readiness to use and test a "toolbox" is highly dependent on the type of user and his or her technical background, we designed the system based on use cases and user typology. As a result, we suggest a framework of open, freely available, easy-toinstall, single and multi purpose PM software tools which can be selected solely on a need basis. With this free platform we want to guide practitioners through the tool jungle with the potential to grow into a lively community.

Index Terms-Business Community, Project Management, SME, Toolbox, User Stories

\section{INTRODUCTION}

Social Media has become a main part of private life and business. For recruiting processes and marketing activities it's getting more and more common, to integrate Social Media in the mix of possibilities to reach the target group. For learning and knowledge management E-Learning and Social Learning Tools have been used for years. In other areas like project management, it is still common practice to use specific and expensive software to manage all tasks, but social media are becoming more popular (Harrin 2012). For Small and Medium Sized Enterprizes (SMEs) the software is often oversized (Santex 2009): they just need project management tools that fit their needs.

Most of the available project management software offers a broad range of detailed specific project tasks. The people in the project are only able to work on the project together if all have access to the software. This is espe- cially important if they work in different units or different companies with different technical equipment and background. Especially in distributed, international teams, the quality of communication and collaboration is a critical factor for the success of the projects. Taking this into account, open source software and social media tools could fill a gap between the oversized software on the one hand and the „I-use-Excel-for-this“-solution on the other hand.

Because of these identified gaps we have developed a project management (PM) toolbox within the research project InterComp SME 2.0 at the Berlin School of Economics and Law (BSEL). It addresses professionals at SMEs who are looking for smart solutions to manage their projects. This web based content management system is the result of the first one and a half years of research within this corporate project in the field of E-Learning. Funded by the Germany Ministry of Education and Research and together with its science and business partners, this project focuses on the development of modularized training offers for SMEs at the interface of information technology and culture (Birkenkrahe, 2009).

How a transfer of traditional training situations into an international project environment in a virtual 3D world could work, was shown by us in an earlier work (Birkenkrahe, Habermann, Quade, 2011). Experience with practice supervision courses in Second Life at the Berlin School of Economics and Law was adapted to IT project situations exemplarily simulated for a client software training situation. Later, Birkenkrahe, Kjellin and Quade (2011) argued that a formalized context can inspire people to transfer knowledge when collaborating. In the remainder of this paper we will use the example of a PM toolbox to investigate three key questions:

1. Do the project manager practitioner have a need for picking tools, especially in SMEs?

2. Which user types can be classified in terms of technical background?

3. How can we support these needs with our research approach?

\section{METHODS}

To develop the PM Toolbox within the research project InterComp SME 2.0, we opted to separate the business and the IT aspects, and we chose different methodologies better adapted to the specific circumstances of the problem setting (see Fig. 1 for an overview). 


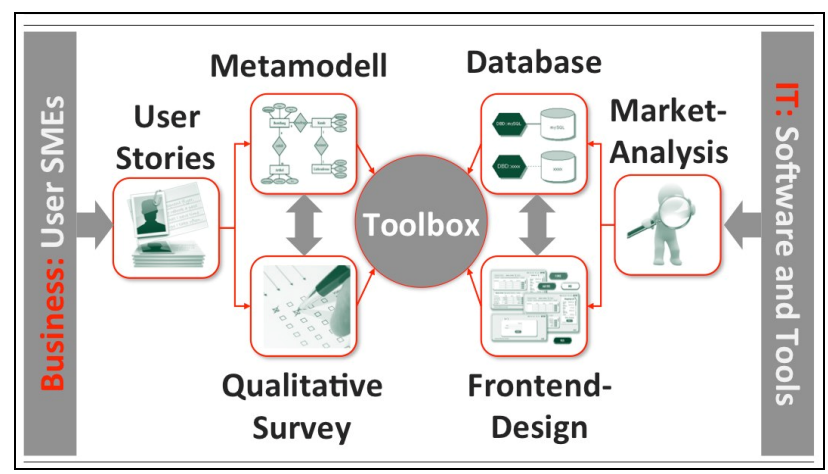

Figure 1. Methodological Model

\subsection{The Business Perspective}

From the Business Perspective three distinct methods were selected:

(a) user stories

(b) qualitative survey

(c) meta model

(a) The method of user stories (Cohn, 2004) were adapted to put a focus on the real user cases of project manager. Gained from business practices master- and bachelor students (management and IT) and also employees of small and medium sized companies with different professions and areas of authorities were interviewed (n > 100). The user story follows the structure:

As [ROLE] I want [GOAL/DESIRE], so that [BENEFIT]

By describing the subject-specific application or use case the user and their tasks/roles become a focused part. The user stories are formulated in generic phrases. These stories are a proven starting point to develop a more detailed software specification.

(b) To get a deeper insight of the needs of project manager from Small and Medium sized companies a qualitative survey was undertaken. The aim of the investigation was to get a comprehensive picture of their needs related to IT-solutions in project management. To conduct this, a semi-structured qualitative interview was chosen (Mayring 2002). Ten experienced project manager from different industries and different sized SMEs run the interview, which was conducted in appr. one hour each via a skype call or physically at the office of the project manager. All interviews were recorded with a recording application on an iPad. Each of the interviewees answered a one page sheet with 10 questions relating their project management background in their working field in advance. The participants received a cover letter and a participant information sheet, which prepared them for the 1-hour interview. The interviews were transcribed and anonymized before the results were analyzed.

(c) The meta model structured the findings out of the user stories and the qualitative survey. Elements which are mainly important for small and medium sized companies were identified and meta-modelled. To validate the metamodel a study of the available literature was used (Scheer, 2001) to ensure the completeness and correctness of all elements and relations.

\subsection{The IT Perspective}

In order to connect the business research with the state of the market and the technology, three distinct methods were employed while developing the IT platform:

(d) market analysis

(e) database

(f) frontend design

(d) The market of available open source project management software was researched. Project management communities and forums have been a relevant source of finding different software. After this first market research the open source products were analyzed and the platform presentation was structured according to categories derived from the tasks of a project manager. In addition to this relevant social media tools were researched and also task-based categorized.

(e) The market analysis and the findings of the business perspective provided the framework for the database. The structure followed the categorized tasks of the project management software analysis. New subcategories were created and adjusted accordingly to the user stories and expert interviews.

(f) The frontend was designed according to the demands that were gained out of all research parts both from the business and IT side. The entry to the database on the website shows three different main user types according to the results of (a) and (b) using the persona method (Cooper, 2010).

This tri-fold method model works as Participatory Action Research (PAR) in the sense of Freire (BrydonMiller, 2003), with a noted, explicit emphasis on the fact that both participants and researcher were part of the same community and giving rise to an "action-reflection" sequence of research learning. For example, the participants both in the SME and in the university were informed about the purpose and nature of the investigation before and were kept informed during and after the research data were obtained. During the research, the user community was confronted with partial results of our work (types; stories; toolbox). A usability test will involve the community in the next part of the research. With this step the cycle of the participatory action research will move into the next round.

\section{RESULTS}

Because our research brings together two different perspectives, the following chapter presents the results of the precedent surveys of the research project up to the actual point of development of the project management toolbox. The design of the platform itself was built up on the business and IT perspectives.

The business surveys with a special view on the needs and demands of the user side identified the following aspects:

The user were asked to complete the sentence within the background of project management "I need a tool to ..." or "I need a tool so that ...".

The valid answers (a total of 107 responses) were categorized by frequentness of the tasks (see fig. 2). Four main categories were identified: 
- $\quad$ Files and documents

- Communication

- $\quad$ Creativity Tools

- Organization

These main categories were adapted for the webpage as entrance to the tool-database (see fig. 3).

The qualitative business survey was based on the project management background of the participant and their company, technical background and IT solutions in their project word. Which IT tools do they use for supporting their project tasks? What are the advantages and disadvantages of theses IT solutions? Which social media and open source software do they know and how do they include them in their daily work. A special aspect in the interview guideline was the invitation to let the user tell their story of the last project (Birkenkrahe, Kjellin, Quade 2011). At the end of the story the interviewer asked a "imaginary wand" question: the project manager could state three wishes for IT based solutions they could imagine even if they thought this wouldn't be possible. They were requested to act as if the interview would be a fairy tale. The user stories and their imaginations turned into a detailed market research of relevant tools according to these special wishes. One example is the wish of a participant, to get an translated chat for international project groups. The research team found "babelwith.me" (livechurch 2009), an instant online translation chatroom, where sender and receiver can choose the language they want to read (see fig. 4).

Next to the wishes and outcomes of the qualitative interview and user stories, the research team surveyed the market of social media tools and open source software, which fit to the identified projekt management tasks. The retrieved data were selected by single and multi purpose tools (see fig. 5). That means tools which solve one special task, e.g. Google Docs as a single purpose tool to work collaborativly and simultaneously on a document.

The market research resulted in 20 multi purpose tools and 60 single purpose tools. All selected tools were categorized in the above mentioned first-level-structure:

- $\quad$ Files and documents

- Communication

- Creativity Tools

- Organization

Each tool was entered in the database with its logo, link and a description, how it could be used for project management (see fig. 6). The community-based approach allows the user to the tool employing a five-star system.

\begin{tabular}{|l|r|}
\hline \multicolumn{1}{|c|}{ Total number of answers: } & 107 \\
\hline & \\
\hline User Story: & $\begin{array}{l}\text { Number of } \\
\text { I need a tool to.../ I need a tool that... }\end{array}$ \\
\hline create work packages & 2 \\
\hline plan actions, update and analyse the on-going situation & 2 \\
\hline organise my work and priorities & 2 \\
\hline remind and motivate me to achieve goals & 1 \\
\hline visualize project milestones / results & 2 \\
\hline helps to prioritize tasks & 1 \\
\hline
\end{tabular}

Figure 2. User Story
As a database, we used MySQL as an integrated part of the Drupal Content Management System. This open software allowed the research team to assemble the concept of the project management toolbox very flexibly.

We designed the system based on use cases and user typology based on the qualitative analysis. The survey revealed that the readiness to use and test some tools is highly dependent on the type of user and his or her technical background.

These three user typologies (see fig. 7) are linked to a mix of social media tools of different categories. The user typology describes the three main types according to Cooper (2004):

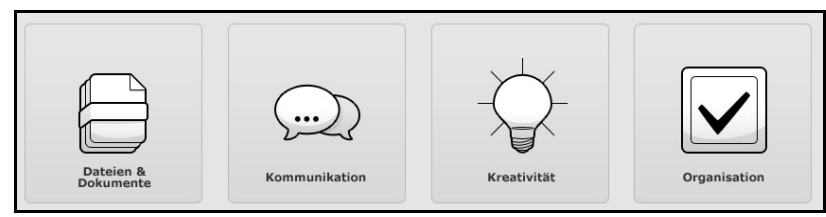

Figure 3. screenshot: Tool Categories

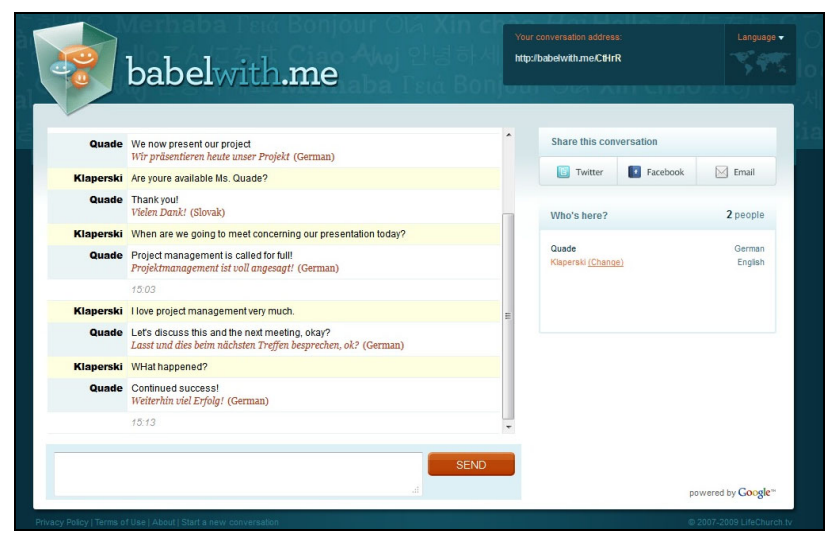

Figure 4. babelwith.me, a translator application

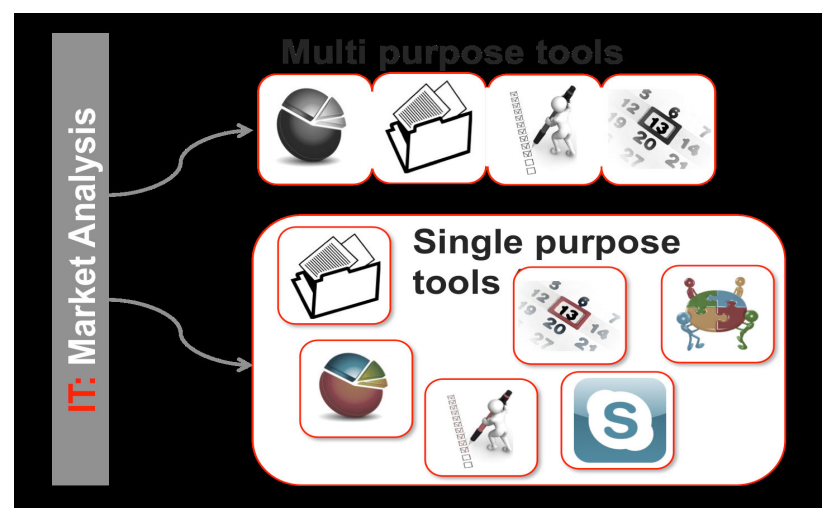

Figure 5. Multi and Single Purpose Tools

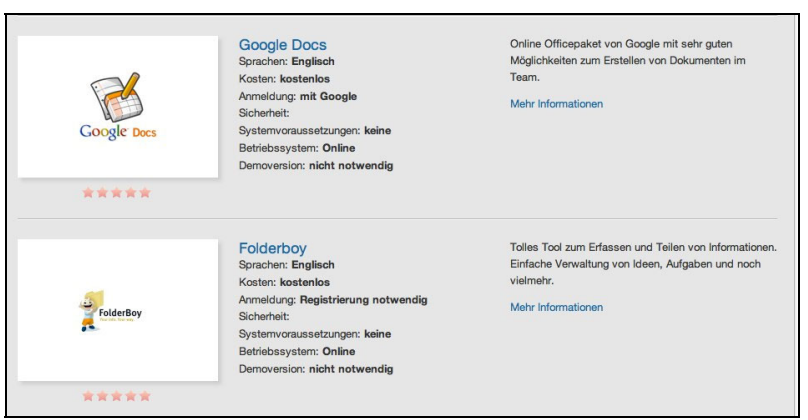

Figure 6. Screenshot: tools in the Database 
- $\quad$ beginner (Laura, Marketing Manager):

"For my marketing-projects, I need ready-to-use tools. It has to be simple and fast, otherwise I'll stay at MS office and Email”

- $\quad$ intermediate (Martin, Project Manager):

"Projectmanagement is my passion. I need perfectly fitting tools for my project management tasks.”

- $\quad$ expert (Kaya, IT Manager):

"As an expert I know what's state-of-the-art on the software market. For my projects I need innovative solutions, which convince me."

The name for each character was taken from the list of most popular names of the 1970s, which symbolizes our main target group. The winners were one male (Martin), one female (Laura) and the unisex Kaya, which could stand for a male or a female. Drupal allows to easily update the tool mix, which is crucial as social media tools are still changing rapidly.

According to all research findings, the research team designed the starting page to the tool database on the PM toolbox website (see fig. 8), for the target audience, practitioner in SMEs:

a) by user typology

b) by category icons

After the launch of the (for now) German-language website the user will have the possibility to find the right project tool for his or her specific project need and share his and her thoughts about the tool solution within the community of PM practitioner.

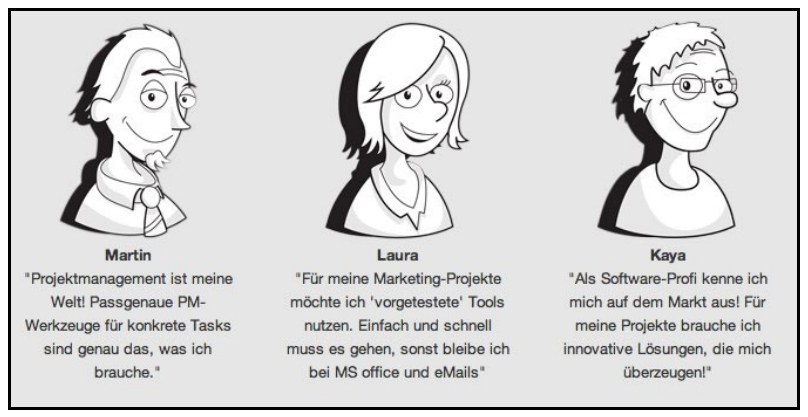

Figure 7. Screenshot: User Typology

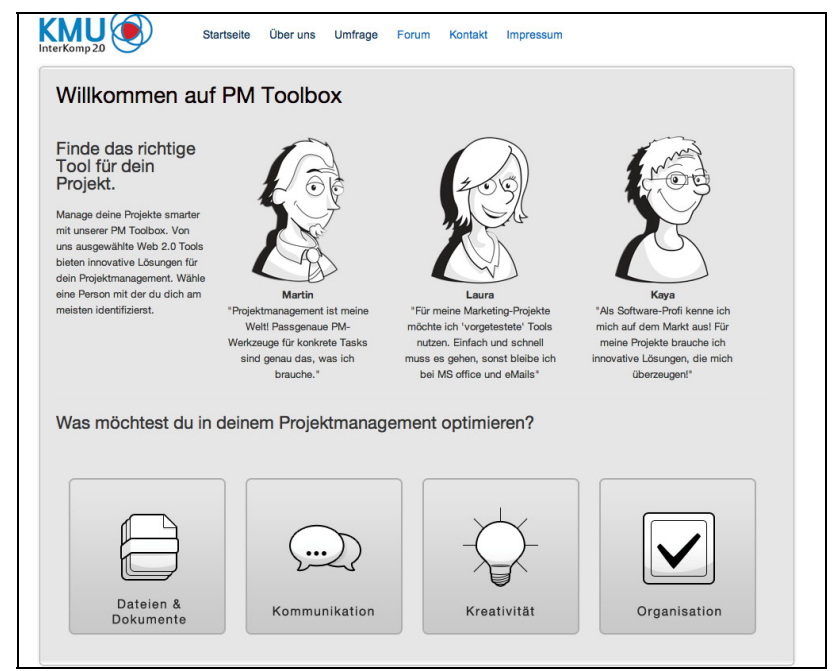

Figure 8. Screenshot: Project Management Toolbox Website

\section{DISCUSSION}

The purpose of this research survey was to investigate the demand for project manager of SMEs who deal with international and/or distributed, virtual teams. Concerning their need of communication and collaboration and the requirement of specific technical skills of the user, the overall results show that there is a high demand for the right tools. In addition, it is important to distinguish user types with regard to the technical skill background.

\section{Do the project manager practitioner have a need} for picking tools, especially in SMEs?

The business surveys have shown that the commercial available project management software is often too oversized for small and medium sized companies. Next to the demand for single purpose tools especially for individual tasks, open source solutions as multi purpose tools for a group of tasks fit the needs of the practitioner.

\section{Which user types can be classified in terms of} technical background?

Depending on the technical skills of each user, three different main user types were classified (beginner, intermediate, expert). The decision to design the entry of the website via user typologies was based on the resulting user stories and our qualitative research results.

\section{How can we support these needs with our re- search approach?}

To develop the database, the results of the business and IT perspective suggested the structure and the categories for the single and multi purpose tools. The overall design with the two-way entry by user typology and by category icons supports the need for tools which can be selected solely on need.

\section{CONCLUSIONS}

The approach of the project management toolbox has added value in the context of workplace learning. The website delivers a free platform which guides practitioners through the tool jungle. In this paper the focus was on the design and development of the content management system describing why and how the website has grown this way.

However, further research is necessary. Next steps of the InterComp SME 2.0 research team will be to test the usability and to launch the website. During a student project, learning videos for each tool will be created and embedded on the website. Further action reflections as part of the systemic action research will deliver more results about the usability and the market relevance of the research approach.

To activate the target group to use the website, the research team will launch and promote the PM Toolbox in project management organizations, magazines and relevant websites and social media channels.

Another future opportunity will be the "Patenschaft" (adoption) of a tool. Either the producer of the social media or open source product or an interested expert user will be asked to keep the embedded information up to date. A community member can get the developer rights on "adopted" tools with his profile from the administration. 
The PM Toolbox holds the potential to grow into a lively community whose members will keep the toolbox up to date.

\section{REFERENCES}

[1] Birkenkrahe, M., Scholl, M. (2009), Konzipierung von modularen Weiterbildungsangeboten für KMU an der Schnittstelle von Technik und Kultur zum Thema "Internationales IT-gestütztes Projektund Wissensmanagement im multikulturellen Umfeld", Berlin School of Economics and Law, Technical University of Applied Science Wildau

[2] Birkenkrahe, M., Kjellin, H., Quade, S. (2011): Applying a formalized context to inspire people to develop transferable descriptions of knowledge, in: Proceedings of the 5th GUIDE International Conference, Italy, Rome, Nov. 2011

[3] Birkenkrahe, M., Habermann, F., Quade, S (2011): Improving Collaborative Learning and Global Project Management in Small and Medium Enterprises, ICELW 2011 - International Conference on E-Learning in the Workplace, New York, June 2011, (iJAC)",Vol 4, No 4/2011

[4] Brydon-Miller M., and Greenwood, M. (2003) Why Action Research? http://arj.sagepub.com/content/1/1/9.short

[5] Cavana, R., Delahaya, B., and Sekaran, U. (2001), Applied Business Research: Qualitative and Quantitative Methods, Milton, John Wiley \& Sons Australia Ltd., p. 148-153

[6] Cohn, M., 2004, User Stories Applied: For Agile Software Development, Addison-Wesley Professional; Boston, MA 02116, 1st ed., p. 45

[7] Cooper, A., 2004, Inmates Are Running the Asylum, The: Why High-Tech Products Drive Us Crazy and How to Restore the Sanity, Sams Publishing

[8] Cooper, A., Reimann, R., Cronin, D. (2010), About Face: Interface und Interaction Design, mitp, Heidelberg, p. 100-126

[9] Drupal Content Management Software, http://drupal.org/
[10] Habermann, F. (2011), Netzwerke 2.0 - Management zwischen Ordnung und Chaos (Networks 2.0 - Management between order and chaos), in: IM - Information \& Management Volume 69, Issue 4/2011, pp.65-70

[11] Harrin, E. (2012), Social Media For Project Managers, Interview 21.01.12, www.guerrillaprojectmanagement.com

[12] LifeChurch.tv, (2009) babelwith.me, http://www.babelwith.me/

[13] Mayring, P. (2002), Einführung in die Qualitative Sozialforschung, S. 80-85, Beltz Verlag

[14] SantexQ, August 17 2010, quotes from GigaOM.com, http://bit.ly/a3bJ2L (accessed 10 May 2011)

[15] Scheer, A.W. (2001), ARIS - Modellierungsmethoden, Metamodelle, Anwendungen, Springer Berlin Heidelberg; Auflage: 4. Aufl. (1. März 2001)

\section{AUTHORS}

Stefanie Quade is with the Department of Economics, Berlin School of Economics and Law, Badensche Str 52, 10825 Berlin, Germany (e-mail: stefanie.quade@hwrberlin.de).

Marcus Birkenkrahe is with the Department of Economics, Berlin School of Economics and Law, Badensche Str. 52, 10825 Berlin, Germany (e-mail: msb@hwr-berlin.de).

Frank Habermann is with the Department of Economics, Berlin School of Econosmics and Law, Badensche Str 52, 10825 Berlin, Germany (e-mail: frank.habermann@hwr-berlin.de).

This article is an extended version of a paper presented at the conference ICELW2012, held June 2012, at Columbia University, in New York, NY, USA. This work was supported in part by the German Federal Ministry of Education and Research (BMBF / FHProfUnt) research programme InterComp SME 2.0. Received 11 May 2012. Published as resubmitted by the authors 05 August 2012. 